\title{
A focus on the features of polyaniline nanofibres prepared via developing the single crystals of their block copolymers with poly(ethylene glycol)
}

\author{
MARYAM NAZARI ${ }^{1}$, SAMIRA AGBOLAGHI ${ }^{2} *$ (D), HOMA GHEYBI ${ }^{3}$, SALEHEH ABBASPOOR $^{3}$ \\ and FARHANG ABBASI ${ }^{3}$ \\ ${ }^{1}$ Department of Chemistry, University of Calgary, Calgary, Canada \\ ${ }^{2}$ Chemical Engineering Department, Faculty of Engineering, Azarbaijan Shahid Madani University, Tabriz, Iran \\ ${ }^{3}$ Institute of Polymeric Materials and Faculty of Polymer Engineering, Sahand University of Technology, Tabriz, Iran \\ *Author for correspondence (chemang96sa1987@yahoo.com)
}

MS received 2 January 2017; accepted 14 June 2017; published online 5 February 2018

\begin{abstract}
Poly(ethylene glycol) (PEG)-polyaniline (PANI) diblock and triblock copolymers were synthesized via copolymerization of aniline with amine-terminated PEG by interfacial polymerization using sulphuric acid as dopant and ammonium peroxydisulfate (APS) as well as potassium hydrogen diiodate (PHD) as oxidants. The PHD-based synthesized PANI nanorods possessed longer lengths, narrower diameter distribution and higher conductivity. The electroactivity of synthesized copolymers was characterized using ultraviolet-visible (UV-Vis) spectrometry, cyclic voltammetry (CV) and resistivity measurement. Even in the presence of dielectric PEG blocks, the synthesized block copolymers had a conductivity around $3 \mathrm{~S} \mathrm{~cm}^{-1}$. In a further step, the solution-grown single crystals were prepared to investigate the general features of grafted PANI nanorods using small-angle X-ray scattering (SAXS), transmission electron microscopy (TEM) and atomic force microscopy (AFM). Based on AFM and SAXS analyses, the bimodal gel permeation chromatography (GPC) traces obtained from the block copolymers were originated from the diameter distribution of nanofibres, not from the dispersity of their lengths and molecular weights.
\end{abstract}

Keywords. Polyaniline; poly(ethylene glycol); block copolymer; nanofibre; interfacial polymerization; single crystal.

\section{Introduction}

Polymer nanostructures [1-3], particularly conducting polymer nanowires and nanofibres [4-6] have recently attracted more interest. Polyaniline (PANI) is unique among the family of conducting polymers due to its ease of synthesis, environmental stability and simple doping/dedoping chemistry [7-9]. Hence, a control over the properties such as free volume [10], solubility [11], electrical conductivity [12] and optical activity $[13,14]$ is easily feasible. Different methods including template method [15], seeding method [16], interfacial polymerization [17], rapid mixing reaction [18], dilute polymerization [19], electrochemistry method [20], surfactants [21-23], coagulating media [24,25] and oligomer-assist polymerization $[17,26,27]$ were proposed to synthesize onedimensional (1D) nanostructured PANI. Syntheses of 1D polyaniline nanostructures were carried out both chemically and electrochemically by the polymerization of monomer with either hard (zeolite channels [28], track-etched polycarbonate $[29,30]$ and anodized alumina $[29,31]$ ) or soft (surfactants [32], micelles [22,33,34], liquid crystals [35], thiolated cyclodextrins [36] and polyacids [37]) templates. The physical methods including electrospinning $[1,38]$ and mechanical stretching [39] were also used to develop the PANI nanofibres. Among these synthesis methodologies, the interfacial polymerization proposed by Huang et al [40] is the most facile as well as template-free approach to synthesize the high-quality PANI nanofibres. The interfacial polymerization could be performed at low temperature with bounded side reactions and results in pure and uniform PANI nanostructures in bulk quantities. These nanostructures have small diameters (around $100 \mathrm{~nm}$ ) [26]. In this method, the secondary overgrowth is restricted through migration of the hydrophilic PANI nanofibres to the aqueous phase and leaving the interface for the directional polymerization reaction. The ease of interfacial polymerization makes it the preferred technique in many fields ranging from microencapsulation of pharmaceutical products to the synthesis of conducting polymers $[26,41]$. From the perspective of electronic potential applications, polyaniline is a unique conjugated 
polymer, which can be tailored for specific applications through a non-redox acid/base doping process [40]. PANI was extensively studied for applications in many areas like electrochromic devices, rechargeable batteries, electromagnetic interference shielding, electrochemical capacitors and ion-sensitive floating-gate field effect transistors [42-45]. The processability and doping properties of PANI could be further improved by combining the electron-conductivity of PANI and the ion-conductivity of poly(ethylene glycol) (PEG) via covalent bonding [46-49]. The self-assembly of the PEG- $b$ PANI and PANI- $b$-PEG- $b$-PANI block copolymers could also reflect control of the structural and morphological properties of PANI nanorods $[46,50]$.

Crystallization, which considerably alters the physical and mechanical features of polymer systems, begins with the attraction of a part of one chain and ends with its incorporation into a crystal lattice in a chain-folded fashion [51]. Different morphologies of the crystalline state, ranging from axialites and dendrites to spherulites, can be obtained from concentrated solutions or from polymer melts. However, the crystallization of well-defined, uniform and high-quality single crystals can be achieved in the supercooled dilute solutions, and mostly by the self-seeding method [51-57]. Among various methods for developing the polymer brushes (tethered chains on a substrate) comprising grafting to [58-62], grafting from [63-65], and single crystal growth of block copolymers [52,56,66-68], the latter approach can accurately control and tune the uniform distribution of tethered brushes $[51,52,56,66,69-74]$. So far, there is a limited literature on the polymer semiconductor single crystals or highly crystalline self-assembled nanostructures, for example, poly(3-hexylthiophene) (P3HT) [75], poly(3butylthiophene)- $b$-polyethylene (P3BT- $b$-PE) [76] and PANI- $b$-PEG- $b$-PANI [46]. In this work, the features of the PANI nanofibres were investigated using growth of the PEG- $b$-PANI and PANI- $b$-PEG- $b$-PANI single crystals in a dilute solution. The characteristics of the PANI nanofibres were correlated to the ultimate results acquired from the corresponding single crystals.

\section{Experimental}

\subsection{Materials}

The PEGs with various molecular weights $\left(M_{\mathrm{n}}=5000,6000\right.$ and 35,000 $\mathrm{g} \mathrm{mol}^{-1}$ ) and 4-amino-benzoic acid were dried under vacuum before use. Xylene (Merck) was dried completely and refluxed under an inert atmosphere by a constant flow of nitrogen. Aniline (Merck) was distilled under reduced pressure before use. Methanol, sulphuric acid, ammonium peroxydisulfate (APS), $p$-toluenesulfonic acid (PTSA) and chloroform were purchased from Merck and used as received. Potassium hydrogen diiodate (PHD) was purchased from Sigma Aldrich.

\subsection{Synthesis}

2.2a Amine-terminated PEG: Amine-terminated PEGs (ATPEGs) were synthesized as macroinitiators from different molecular weights of PEG $\left(M_{\mathrm{n}}=5000,6000\right.$ and $35,000 \mathrm{~g}$ $\mathrm{mol}^{-1}$ ), 4-aminobenzoic acid PTSA in the catalytic amount by refluxing with xylene. The solid ATPEGs were named as $\mathrm{ATPEG}_{5000}, \mathrm{ATPEG}_{6000}$ and $\mathrm{ATPEG}_{35000}$. These three macroinitiators were synthesized by the following procedure. The PEG, 4-aminobenzoic acid and xylene were taken into a two-necked reaction flask equipped with a stirrer, a thermometer pocket and a Dean and Stark trap. The catalytic amount of PTSA was then added to the mixture. The mixture was heated to reflux temperature $\left(140^{\circ} \mathrm{C}\right)$. The generated water of the reaction was removed as an azeotrope until the reaction is completed as indicated by no further formation of water. It needed refluxing at $140^{\circ} \mathrm{C}$ for $5 \mathrm{~h}$. The solvent was then distilled off and the solid product was dissolved in chloroform $[47,77]$. Then, the residue of the solvent was removed off under reduced pressure and the solid product was dissolved in chloroform. Then, the unreacted 4-aminobenzoic acid was filtered, and the final solid product was dried in vacuum for $48 \mathrm{~h} \mathrm{[77].} \mathrm{The} \mathrm{detailed} \mathrm{amount} \mathrm{of} \mathrm{materials} \mathrm{used} \mathrm{to} \mathrm{synthe-}$ size $\mathrm{APEG}_{5000}, \mathrm{ATPEG}_{6000}$ and $\mathrm{ATPEG}_{35000}$ are reported in supplementary table S1.

2.2b Copolymers: The PANI ${ }_{n}-b$-PEG- $b$-PANI ${ }_{n}$ and PEG$b$-PANI ${ }_{n}$ block copolymers were synthesized by an interfacial polymerization $[17,46,47]$. The employed indices for denoting the molecular weight of the synthesized block copolymers were based on ${ }^{1} \mathrm{HNMR}$ analysis. The APS or PHD was dissolved in $1 \mathrm{M}$ sulphuric acid solution in a $400 \mathrm{ml}$ beaker. Then, it was gently added along the sides of the beaker containing a solution of aniline and macroinitiator in chloroform at $6^{\circ} \mathrm{C}$. Different aniline/ATPEG ratios were utilized to reach different molecular weights for the PANI blocks. The aniline/ATPEG/chloroform solution formed the lower organic layer and APS/PHD solution formed the upper aqueous layer. After a short induction period (within $1 \mathrm{~min}$ for the APS-based batches and 15 min for the PHD-based batches), green polyaniline appeared at the interface, migrated into the water phase, and finally filled the entire water layer. As the reaction proceeded, the colour of the organic phase became darker and finally stopped changing at the end of the reaction. Then, the solid polymer consisting the PANI homopolymer and PANI $n-b$-PEG- $b$-PANI $n$ /PEG$b$-PANI $n$ block copolymers was filtered. The unreacted PEG remained from esterification step was soluble in chloroform and could not enter into the structure of copolymers. This precipitate was poured into methanol, the PANI homopolymer was insoluble in methanol, but PANI ${ }_{n}-b$-PEG- $b-$ PANI $_{n} / \mathrm{PEG}$ $b-\mathrm{PANI}_{n}$ was soluble in this solvent. The mixture was then stirred for $12 \mathrm{~h}$ and filtered. The solid PANI homopolymer was removed off and the resulting dark brown solution was poured into cold diethyl ether to precipitate the final polymer. The block copolymer isolated by filtration was quite dried at 
$30^{\circ} \mathrm{C}$ under vacuum. The synthesis of PEG- $b$-PANI ${ }_{n}$ diblocks using poly(ethylene glycol) mono methyl ether required half of the aniline amount that was employed to synthesize the PANI $_{n}-b$-PEG- $b-$ PANI $_{n}$ triblock copolymers.

\subsection{Single crystal growth}

The single crystals covered by the conductive PANI nanorods were grown using self-seeding procedure including four thermal steps, i.e., dissolution $\left(T_{\mathrm{d}}=65^{\circ} \mathrm{C}\right.$ for $\left.30 \mathrm{~min}\right)$, primary crystallization (at $0^{\circ} \mathrm{C}$ for $5 \mathrm{~h}$ ), self-seeding $\left(T_{\mathrm{s}}=41^{\circ} \mathrm{C}\right.$ for $20 \mathrm{~min}$ ) and isothermal secondary crystallization (at desired $T_{\mathrm{c}}$ for 3 days) temperatures. More details about the selfseeding procedure were reported elsewhere $[46,70,72-74]$.

\subsection{Instrumentation and measurements}

The syntheses were proved by Fourier transform infrared spectroscopy (FTIR) on Bruker (Tensor 27) spectrometer. The FTIR spectra of $\mathrm{PANI}_{8748}-b-\mathrm{PEG}_{6000}-b-\mathrm{PANI}_{8748}$ and $\mathrm{PANI}_{9003}-b-\mathrm{PEG}_{6000}-b-\mathrm{PANI}_{9003}$ block copolymers are represented in supplementary figure S1a and b, respectively. For the $\mathrm{PANI}_{8748}-b-\mathrm{PEG}_{6000}-b-\mathrm{PANI}_{8748}$ triblock copolymers, the two bands occurring around 1645 and $1496 \mathrm{~cm}^{-1}$ were attributed to the stretch of the quinoid and benzenoid rings, respectively. These two peaks confirmed the polymerization of aniline and formation of block copolymers [78,79]. The carbonyl bonds of the block copolymers were appeared at $1696 \mathrm{~cm}^{-1}$ [47]. The stretching bonds of the aliphatic $-\mathrm{CH}$ and the stretching bonds of the aromatic $-\mathrm{CH}$ were characterized at 2929 and 3055 $\mathrm{cm}^{-1}$, respectively $[47,78]$. The aromatic $\mathrm{C}-\mathrm{H}$ in-plane bending $\left(1401 \mathrm{~cm}^{-1}\right)$ and the out-of-plane deformation of $\mathrm{C}-\mathrm{H}$ in the 1,4-disubstituted benzene ring $\left(883 \mathrm{~cm}^{-1}\right)$ were also observed [80]. The peak at $3457 \mathrm{~cm}^{-1}$ was assigned to the $\mathrm{N}-\mathrm{H}$ or $\mathrm{O}-\mathrm{H}$ stretching vibrations [80]. More details on the determinant peaks of the $\mathrm{PANI}_{9003}-b-\mathrm{PEG}_{6000}-b-\mathrm{PANI}_{9003}$ block copolymers are represented in supplementary information.

The chemical structure and composition of the block copolymers were confirmed by ${ }^{1} \mathrm{H}$ NMR spectroscopy on a Bruker (Avance DPX) spectrometer working at $400 \mathrm{MHz}$ using deuterated water $\left(\mathrm{D}_{2} \mathrm{O}\right)$ as the solvent. The molecular weights of $\mathrm{PANI}_{6748}-b-\mathrm{PEG}_{6000}-b-\mathrm{PANI}_{6748}$ (supplementary figure $\mathrm{S} 2 \mathrm{a}$ ), $\mathrm{PANI}_{9003}-b-\mathrm{PEG}_{6000}-b-\mathrm{PANI}_{9003}$ (supplementary figure $\mathrm{S} 2 \mathrm{~b}$ ), $\mathrm{PEG}_{5000}-b-\mathrm{PANI}_{3120}$ (supplementary figure $\mathrm{S} 2 \mathrm{c}$ ), $\mathrm{PANI}_{10240}-b-\mathrm{PEG}_{35000}-b-\mathrm{PANI}_{10240}$ (supplementary figure S2d), $\mathrm{PANI}_{9003}-b-\mathrm{PEG}_{6000}-b$ - $\mathrm{PANI}_{9003}$ (supplementary figure $\mathrm{S} 2 \mathrm{e}$ ), $\mathrm{PANI}_{3540}-b-\mathrm{PEG}_{6000}-b-\mathrm{PANI}_{3540}$ (supplementary figure S2f), $\mathrm{PANI}_{3165}-b-\mathrm{PEG}_{6000}-b$ - $\mathrm{PANI}_{3165}$ (supplementary figure $\mathrm{S} 2 \mathrm{~g}$ ), $\mathrm{PANI}_{14201}-b-\mathrm{PEG}_{6000}-b$ $-\mathrm{PANI}_{14201}$ (supplementary figure $\mathrm{S} 2 \mathrm{~h}$ ), $\mathrm{PANI}_{14547}-b-\mathrm{PEG}_{6000}$ $-b-\mathrm{PANI}_{14547}$ (supplementary figure $\mathrm{S} 2 \mathrm{i}$ ), $\mathrm{PEG}_{5000}-b$ $\mathrm{PANI}_{2430}$ (supplementary figure $\mathrm{S} 2 \mathrm{j}$ ), $\mathrm{PEG}_{5000}-b-\mathrm{PANI}_{3120}$ (supplementary figure $\mathrm{S} 2 \mathrm{k}$ ), $\mathrm{PANI}_{10050}-b-\mathrm{PEG}_{35000}-b$ $\mathrm{PANI}_{10050}$ (supplementary figure $\mathrm{S} 2 \mathrm{l}$ ), $\mathrm{PANI}_{10240}-b-\mathrm{PEG}_{35000}$
$-b$-PANI 10240 (supplementary figure $\mathrm{S} 2 \mathrm{~m}$ ) and $\mathrm{PANI}_{16520}-b$ $\mathrm{PEG}_{35000}-b$-PANI 16520 (supplementary figure $\mathrm{S} 2 \mathrm{n}$ ) block copolymers were calculated based on the integral ratios of protons of PANI benzene ring (7.2-7.4 ppm) and $\mathrm{CH}_{2}$ protons of PEG (3.5 ppm). The molecular weights of copolymers and homopolymers obtained, while synthesizing copolymers are represented in supplementary tables S2 and S3, respectively.

Furthermore, the molecular weight distributions of the block copolymers were determined by the gel permeation chromatography (GPC) on a WATER 1515 (USA) chromatograph with a set of HT3, HT4 and HT5, $\mu$-styragel columns with dimethyl formamide (DMF) as eluent $\left(1.0 \mathrm{ml} \mathrm{min}^{-1}\right)$ at $40^{\circ} \mathrm{C}$. A set of monodisperse polystyrene standards was utilized for calibration. Nanofibres were de-doped and dissolved

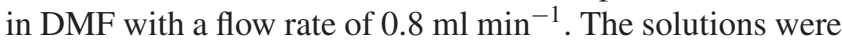
filtered with $0.20 \mu \mathrm{m}$ syringe filters before being injected into the column.

The structures of PANI nanorods and single crystal were detected under a transmission electron microscope (TEM, EM 208 Philips) at low doze condition with an accelerating voltage of $100 \mathrm{KeV}$ and filaments of (electron gun) tungsten. The magnification ranged from $<50 \times$ up to $1,200,000 \times$. The selected area electron diffraction (SAED) experiments were also conducted to determine the chain orientation in the single crystals. Calibration of the SAED spacing values $<0.384 \mathrm{~nm}$ was carried out using evaporated thallous chloride. Spacing values $>0.384 \mathrm{~nm}$ were calibrated by doubling the $d$-spacing values of the first-order diffractions. A standard copper grid was used as a substrate for TEM measurement. Scanning transmission electron microscopy (STEM) experiments were carried out adopting a FEI Quanta 400 operated at $30 \mathrm{kV}$ with a tungsten filament.

To identify the surface morphology of the single crystals, the solution was dropped onto a silicon wafer and quickly dried by a stream of high purity nitrogen and observed under an atomic force microscope (AFM, Nanoscope IIIA). A silicon tip in the tapping mode was utilized. During AFM scanning, the cantilever tip-to-sample force required to be carefully adjusted to avoid damages. For the tip-to-sample force, a large force could lead to tip penetrations into the thin tethered chain layers, and disturb the materials at the layer surfaces. A scan rate of $1 \mathrm{~Hz}$ and a resolution of $512 \times 512$ were selected to take high quality images. The grown single crystals were also characterized using Bruker-AXS Nanostar SAXS with a counts rate of $1000 \mathrm{~s} \mathrm{~s}^{-1}$ per channel and spatial resolution of $400-500 \mu \mathrm{m}$.

Ultraviolet-visible (UV-Vis) spectra were taken by UVLAMBDA 35 at the wavelengths of $0-1000 \mathrm{~nm}$ with 2-chloroethanol as the solvent. The cyclic voltammetry (CV) was performed on Keithley Model 2460 Source Meter SMU using a platinum wire counter electrode and an $\mathrm{Ag} / \mathrm{AgCl}$ reference electrode. The $\mathrm{CV}$ experiment was performed in $1.0 \mathrm{M}$ dodecylbenzenesulfonic acid solution that contained $30 \mathrm{mg}$ of the block copolymers. The cyclic voltammograms were measured between the range of -0.2 and $1.0 \mathrm{~V}(v s . \mathrm{Ag} / \mathrm{AgCl})$ 
at a scan rate of $20-50 \mathrm{mV} \mathrm{s}^{-1}$. Four-point collinear probe (Model $6221 \mathrm{DC}$ and AC current source) was also utilized to measure the conductivity of synthesized homopolymers and block copolymers.

\section{Results and discussion}

\subsection{PANI nanofibres}

While the interfacial polymerization of aniline, PEG- $b$ PANI $n$ and PANI $n$ - $b$-PEG- $b$-PANI $n$ block copolymers were synthesized in the presence of ATPEGs. Upon addition of the acid and oxidant solution to the mixture of ATPEG, aniline and chloroform, the PANI nanofibres were grown from the aniline monomers attached to PEG. In this procedure, the amine end groups of the macroinitiator were substituted by the amine groups of PANI. Because of their hydrophilicity, the PANI nanofibres migrated to the aqueous phase, and dragged the PEG blocks to the same phase with themselves $[46,47]$. Earlier, Huang et al [40] have demonstrated that in the interfacial polymerization, the PANI nanofibres were not in the access of aniline monomers and, consequently, the secondary growth was hampered. Therefore, a nanofibrillar morphology was resulted from the interfacial polymerization. In our systems, the coily PEG blocks were excluded from the PANI nanofibres, and each block possessed its independent morphology. This assumption was proved by developing the single crystals from the mentioned block copolymers; because the crystalline PEG blocks were incorporated into the crystalline substrate and the PANI nanofibres were tethered on the substrate surface as rigid conductive brushes. Furthermore, on the $5 \mathrm{~nm}$ scale of TEM image for the $\mathrm{PEG}_{5000}-b-\mathrm{PANI}_{8430}$ diblock copolymers synthesized by the PHD as an oxidant, a packed interconnected structure was detected for the PANI nanofibres (figure 1a). The PANI nanofibres synthesized by the PHD oxidant were more extended compared to the APSbased nanofibres. As an instance, the PANI nanofibres in the PHD-based $\mathrm{PEG}_{5000}-b$-PANI 8430 block copolymers were more extended than the APS-based $\mathrm{PANI}_{14201}-b-\mathrm{PEG}_{6000}-b$ $\mathrm{PANI}_{14201}$ block copolymers. Figure 1 depicts these two types of PANI nanofibres.

The diameter range of PANI nanofibres synthesized by the interfacial polymerization depends on the employed acidic dopant [81]. On the other hand, the diameter distribution of the nanofibres and their polydispersity are affected by the oxidant type. In this work, the PHD-based PANI nanofibres possessed a narrow diameter distribution compared to the APS-based ones. Considering the uniform length distribution of PANI nanofibres synthesized with PHD, in a similar condition of APS, it was speculated that the PHD oxidant was rapidly involved in the reaction. It was consistent with the results reported in the literature [82]. Hence, upon developing a radical, the nanofibres with the ideal diameter (the highest population) were synthesized up to the final length. However, before growing the PANI nanofibres with the ideal diameter (for the respective acidic dopant) up to the ultimate

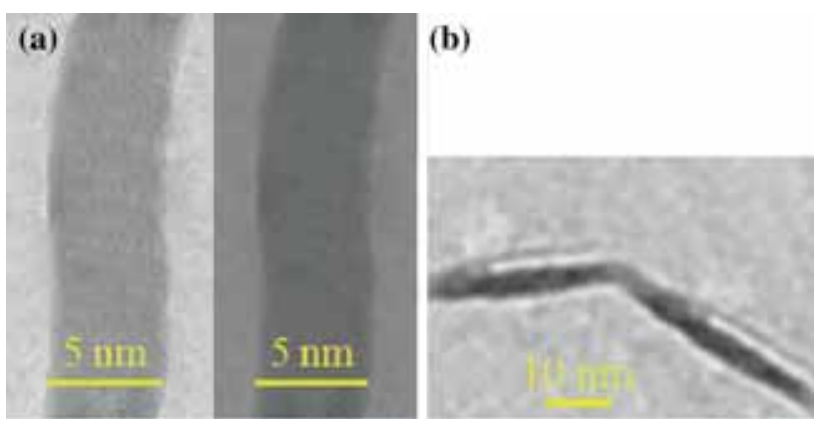

Figure 1. TEM images of (a) PHD-based $\mathrm{PEG}_{5000}-b$-PANI 8430 , bright field (left) and dark field (right); (b) APS-based PANI $14201-b$ $\mathrm{PEG}_{6000}-b-\mathrm{PANI}_{14201}$ nanofibres.

length, the nanofibres with different diameters were synthesized in the presence of APS. On the other side, the PHD oxidant had a more persistent effect on the fabricating radicals of a nanofibre, and led to the longer PANI nanofibres. In our synthesis systems, the dominant diameter in both PHDand APS-based reactions was $32 \mathrm{~nm}$. However, the diameter distribution in APS-based systems was wider than that in PHD-based systems.

In addition to the dopant and oxidant influences, the crosssection (area) of the reactor for the interfacial polymerization was another effective parameter. The larger the interfacial area (cross-section of the reactor), the lower the range of PANI diameters [83]. To eliminate this parameter, all reactions were conducted in $400 \mathrm{ml}$ beakers. The distribution of the PANI nanorods for the APS-based $\mathrm{PEG}_{5000}-b-\mathrm{PANI}_{2430}$ copolymers was in the range of $8-64 \mathrm{~nm}$. In this systems, the diameter of $32 \mathrm{~nm}$ possessed $33 \%$ of the population (figure 2a). By changing the oxidant from APS to PHD (i.e., $\mathrm{PEG}_{5000}-b-\mathrm{PANI}_{3120}$ copolymers), the diameters also ranged in $8-64 \mathrm{~nm}$, but with $80 \%$ of the dominant diameter (figure 2b). In both APS- and PHD-based systems, the dominant diameters were similar $(=32 \mathrm{~nm})$, but with various percentages.

The UV-Vis graphs of undoped PANI nanofibres indicated two characteristic peaks, i.e., 330-340 nm and 610 nm. The former peak was attributed to the repeating units of PANI and in detail, to the electron transfer in benzoidal segments. The latter peak stood for the molecular transitions from quinoidal to benzonoidal, which formed the molecular excitons [84]. The $\mathrm{PEG}_{5000}-b-\mathrm{PANI}_{2430}, \mathrm{PANI}_{3165}-b$ $\mathrm{PEG}_{6000}-b-\mathrm{PANI}_{3165}$ and $\mathrm{PANI}_{3840}-b-\mathrm{PEG}_{35000}-b-\mathrm{PANI}_{3840}$ block copolymers showed the mentioned first peak at 200 , 280 and $320 \mathrm{~nm}$, respectively. They also represented the second peak at 630, 633 and $640 \mathrm{~nm}$, respectively. The shifting in these peaks occurred due to the influence of hydroxyl groups of the solvent and the oxygen of the PEG blocks [47]. Besides these two presented peaks, the synthesized copolymers depicted a third peak at 432, 443 and $445 \mathrm{~nm}$, respectively, for $\mathrm{PEG}_{5000}-b-\mathrm{PANI}_{2430}, \mathrm{PANI}_{3165}-b$ $\mathrm{PEG}_{6000}-b-\mathrm{PANI}_{3165}$ and $\mathrm{PANI}_{3840}-b-\mathrm{PEG}_{35000}-b-\mathrm{PANI}_{3840}$ 

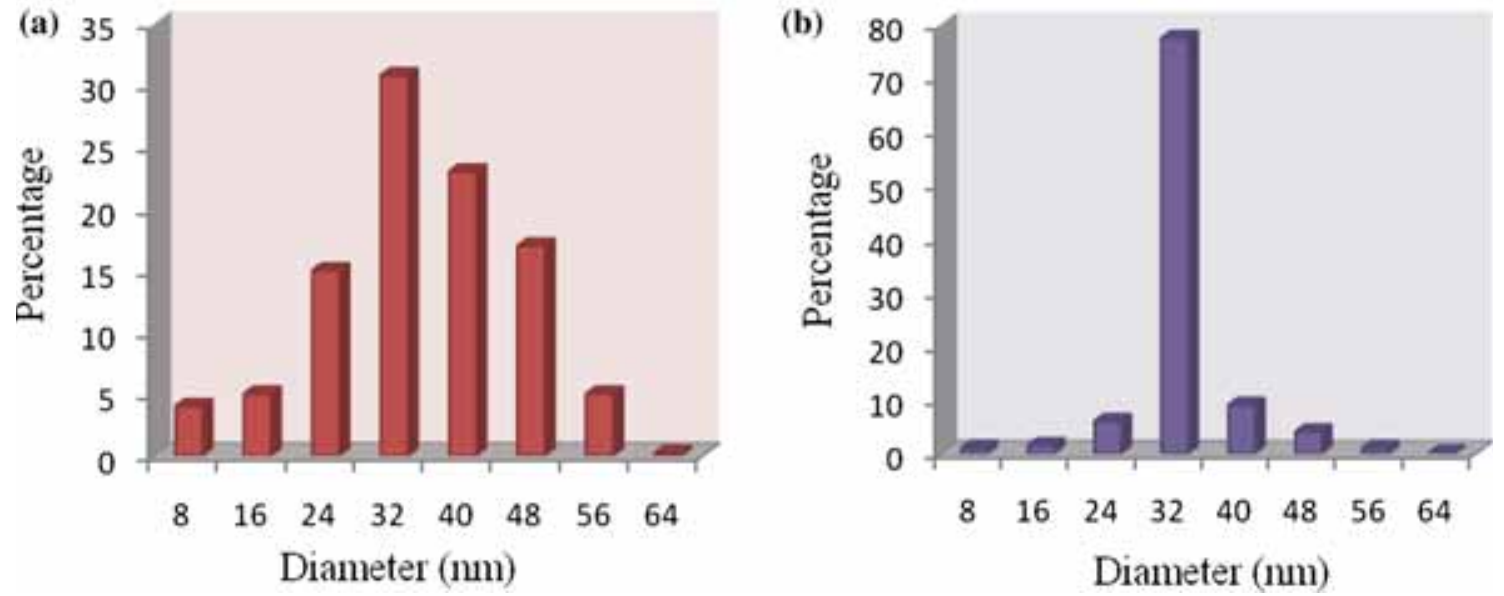

Figure 2. Diameter distribution of (a) APS-based PANI 2430 nanofibres and (b) PHD-based PANI 3120 nanofibres.

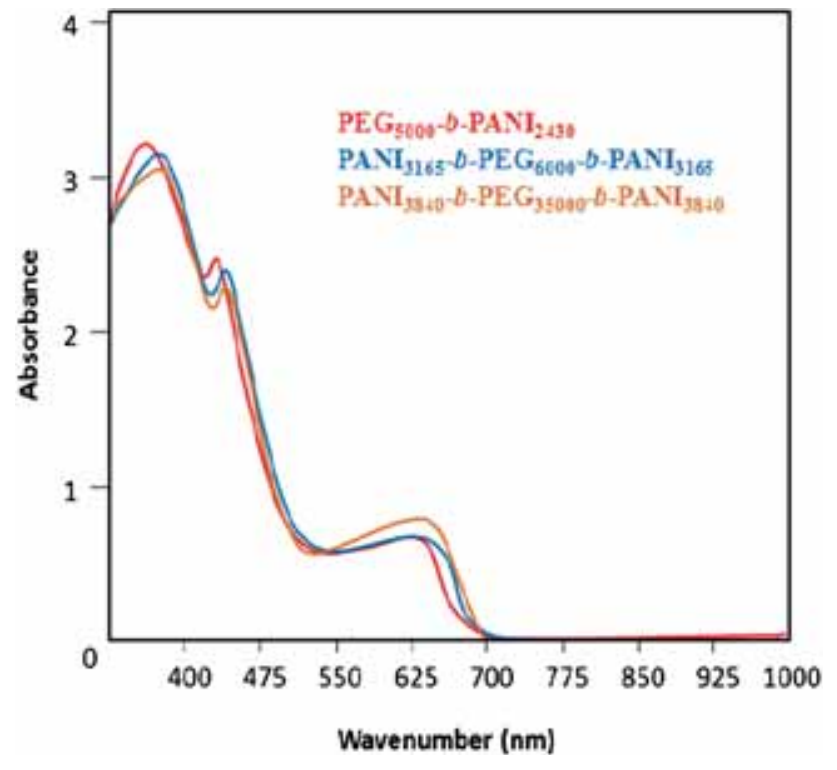

Figure 3. UV-Vis spectra of $\mathrm{PEG}_{5000}-b-\mathrm{PANI}_{2430}, \mathrm{PANI}_{3165}-b$ $\mathrm{PEG}_{6000}-b-\mathrm{PANI}_{3165}$ and $\mathrm{PANI}_{3840}-b-\mathrm{PEG}_{35000}-b-\mathrm{PANI}_{3840}$ block copolymers.

block copolymers. Actually, the doped state of PANI and transitions from valence bands to the polaron band led to these third peaks [85]. According to the original work of Huang et al [7], in PANIs, the charges were spread on the protonated quinoidal diamine units throughout the chains to develop an intermediate state between the benzoidal and quinoidal rings. Hence, in the presence of the dielectric PEG blocks, these transfers became more difficult. Figure 3 represents the UV-Vis spectra of $\mathrm{PEG}_{5000}-b$ $\mathrm{PANI}_{2430}, \mathrm{PANI}_{3165}-b-\mathrm{PEG}_{6000}-b-\mathrm{PANI}_{3165}$ and $\mathrm{PANI}_{3840}-b-$ $\mathrm{PEG}_{35000}-b$-PANI 3840 block copolymers. Furthermore, supplementary figure S3 displays UV-Vis spectra of APS-based $\mathrm{PANI}_{3165}-b-\mathrm{PEG}_{6000}-b-\mathrm{PANI}_{3165}, \quad \mathrm{PANI}_{8748}-b-\mathrm{PEG}_{6000}-b-$ $\mathrm{PANI}_{8748}$ and $\mathrm{PANI}_{14201}-b-\mathrm{PEG}_{6000}-b-\mathrm{PANI}_{14201}$ block

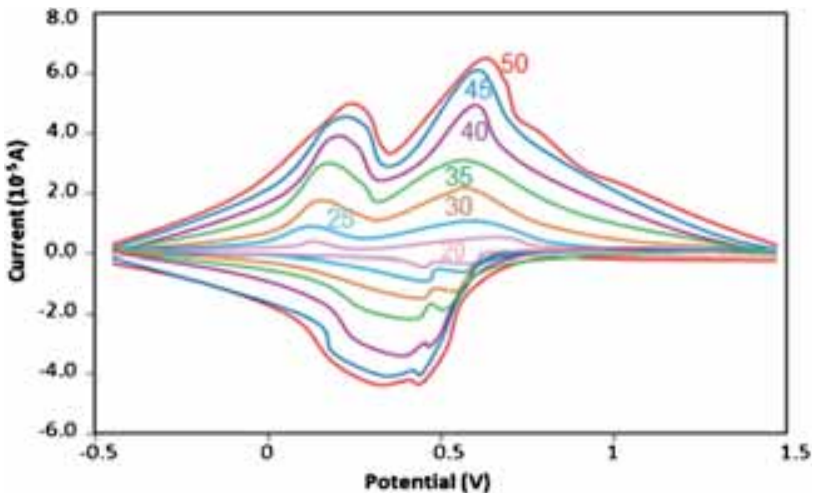

Figure 4. Cyclic voltammetry of $\mathrm{PANI}_{14547}-b-\mathrm{PEG}_{6000}-b$ $\mathrm{PANI}_{14547}$ triblock copolymers synthesized with PHD oxidant in different cycles (sweep rates: 50, 45, 40, 35, 30, 25 and $20 \mathrm{mV} \mathrm{s}^{-1}$ ).

copolymers as well as PHD-based $\mathrm{PANI}_{3540}-b-\mathrm{PEG}_{6000}-b$ $\mathrm{PANI}_{3540}, \mathrm{PANI}_{9003}-b-\mathrm{PEG}_{6000}-b-\mathrm{PANI}_{9003}$ and $\mathrm{PANI}_{14547}-b-$ $\mathrm{PEG}_{6000}-b-\mathrm{PANI}_{14547}$ block copolymers.

The cyclic voltammograms (CV) of the homo PANI nanofibres and their corresponding block copolymers, in general, presented three and two distinct peaks, respectively. For example, in the CV graph of $\mathrm{PANI}_{14547}-b-\mathrm{PEG}_{6000}-b$ $\mathrm{PANI}_{14547}$ triblock copolymers, as illustrated in figure 4 , two distinct peaks were detected. Due to the use of a low sweep rate for the analyses, the middle peak attributed to the degradation of PANIs or ortho PANIs was not detected [86]. The first couple peaks in the CV graphs were for leucoemeraldien to emeraldine transitions. Likewise, the second couple peaks stood for the emeraldine to pernigraniline transitions. In the sweep rate of $50 \mathrm{mV} \mathrm{s}^{-1}$, the first and second oxidative peaks appeared in the potentials of 0.24 and $0.65 \mathrm{~V}$, respectively. Likewise, the first and second reduction peaks occurred in 0.32 and $0.44 \mathrm{~V}$, respectively. A low variance between the oxidation and reduction peaks could be an estimation of a 

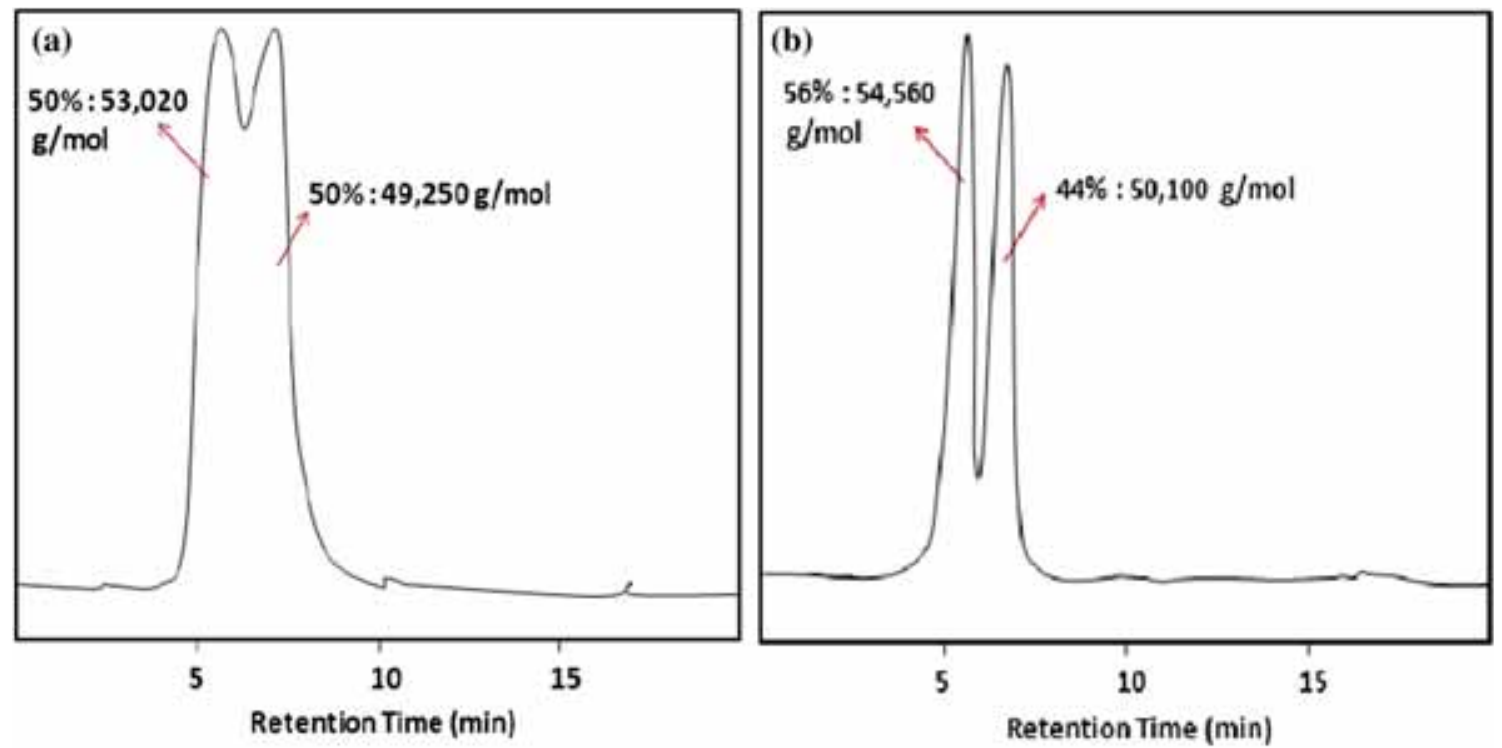

Figure 5. (a) GPC traces of APS-based PANI $16100-b-\mathrm{PEG}_{35000}-b-\mathrm{PANI}_{16100}$ and (b) PHD-based $\mathrm{PANI}_{16520}-b-$ $\mathrm{PEG}_{35000}-b$-PANI 16520 triblock copolymers.

better reversibility of the transition [87]. By increasing the sweep rate from 20 to $50 \mathrm{mV} \mathrm{s}^{-1}$, these graphs became strictly distorted and the distinction of the oxidation and reduction peaks was more considerable [88]. A broad peak was generally an indicative of a difficult transition [87]. In figure 4, the reductive peak from emeraldine to leucoemeraldine became broader by enhancing the sweep rate. This was directly related to this fact that the mentioned chemical transitions became more difficult. Moreover, for the higher sweep rates, the larger voltages were demanded to reach the maximum current. Some other CV graphs are also illustrated in supplementary figures S4 and S5.

The conductivity of PANI nanofibres in both homopolymers and block copolymers were also evaluated. The conductivities of the APS-based PANI ${ }_{14201}-b-\mathrm{PEG}_{6000}-b-\mathrm{PANI}_{14201}$ and PHD-based $\mathrm{PANI}_{16525}-b-\mathrm{PEG}_{35000}-b-\mathrm{PANI}_{16525}$ were $10^{-4}$ and $3 \mathrm{~S} \mathrm{~cm}^{-1}$, respectively. In the respective homopolymers, i.e., APS-based $\mathrm{PANI}_{24300}$ and PHD-based $\mathrm{PANI}_{32200}$, the conductivities were $8 \times 10^{-3}$ and $84 \mathrm{~S} \mathrm{~cm}^{-1}$, respectively. The conductivity ratio of PHD-based nanofibres and APS-based ones was to an extent from the order of $10^{4}$. In addition to the effect of oxidant (PHD or APS), the presence of dielectric PEG chains and their length in the synthesized copolymers influenced the conductivity of PANI nanofibres.

The GPC traces of synthesized block copolymers with both oxidants (APS and PHD) represented two distinct peaks. Furthermore, the molecular weights obtained from ${ }^{1} \mathrm{HNMR}$ and GPC analyses had a consistency of $80 \%$. The overall molecular weights (twice) of PANI blocks for the APSbased $\mathrm{PANI}_{16100}-b-\mathrm{PEG}_{35000}-b$-PANI 16100 triblock copolymers were 25,567 and 32,200 $\mathrm{g} \mathrm{mol}^{-1}$ from GPC and ${ }^{1} \mathrm{HNMR}$ analyses, respectively. Moreover, the overall PANI molecular weights obtained from ${ }^{1} \mathrm{HNMR}$ and GPC for the PHD-based
$\mathrm{PANI}_{16520}-b-\mathrm{PEG}_{35000}-b-\mathrm{PANI}_{16520}$ triblocks were 25,764 and $32,500 \mathrm{~g} \mathrm{~mol}^{-1}$, respectively. Figure $5 \mathrm{a}$ and $\mathrm{b}$ represents the GPC traces of the APS-based $\mathrm{PANI}_{16100}-b-\mathrm{PEG}_{35000}-b$ $\mathrm{PANI}_{16100}$ and the PHD-based $\mathrm{PANI}_{16520}-b-\mathrm{PEG}_{35000}-b$ $\mathrm{PANI}_{16520}$ triblock copolymers, respectively. To date, in the conventional polymers, the bimodal GPC traces were usually assigned to the heterogeneity in the molecular weight distribution. In this work, through the growth of single crystals from the PEG- $b-\mathrm{PANI}_{n}$ and PANI ${ }_{n}-b$-PEG- $b$-PANI ${ }_{n}$ block copolymers, we demonstrated that these bimodal GPC traces had another origin. Supplementary figure S6a and b also depicts the GPC traces of PHD-based PEG $_{5000}-b-\mathrm{PANI}_{8430}$ and APSbased $\mathrm{PANI}_{14201}-b-\mathrm{PEG}_{6000}-b-\mathrm{PANI}_{1420}$, respectively.

By regarding $56-44 \%$ distribution of the surface areas under the two peaks for GPC traces of the PHD-based $\mathrm{PANI}_{16520}-b-\mathrm{PEG}_{35000}-b-\mathrm{PANI}_{16520}$ copolymers and comparing with 50-50\% under peak areas of the APS-based $\mathrm{PANI}_{16100}-b-\mathrm{PEG}_{35000}-b$-PANI 16100 copolymers, the molecular weight dispersities were different in the PHD- and the APS-based systems. We proved that this dispersity for the conductive PANI nanorods occurred because of the diameter distribution. More details are provided in the following sections.

\subsection{Single crystal engineering}

To further investigate the features of synthesized PEG- $b$ $\mathrm{PANI}_{n}$ and $\mathrm{PANI}_{n}-b$-PEG- $b$-PANI ${ }_{n}$ block copolymers, their respective single crystals were developed from various dilute solutions by the self-seeding procedure. It was welldocumented that the PEG single crystals grown from the dilute solutions were square with the dominant growth fronts of $(120)[46,51,52,73]$. In our growth systems, the crystallizable PEG blocks fabricated the folded crystalline 


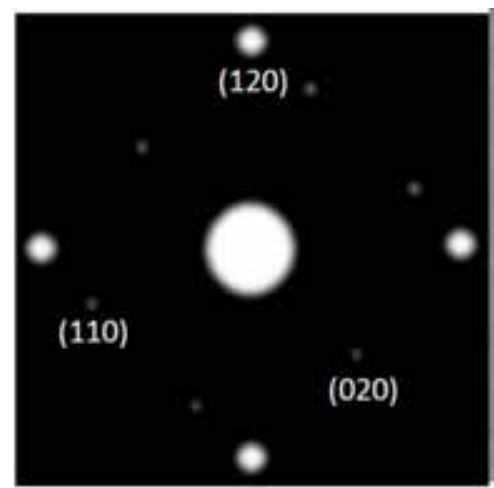

(a)

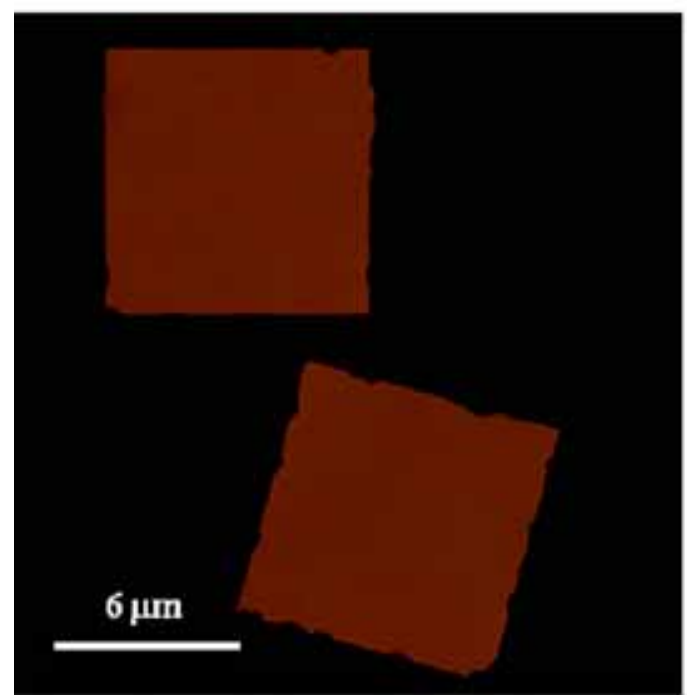

(c)

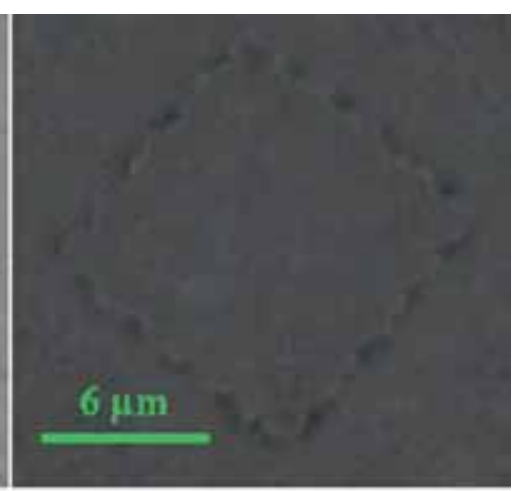

(b)

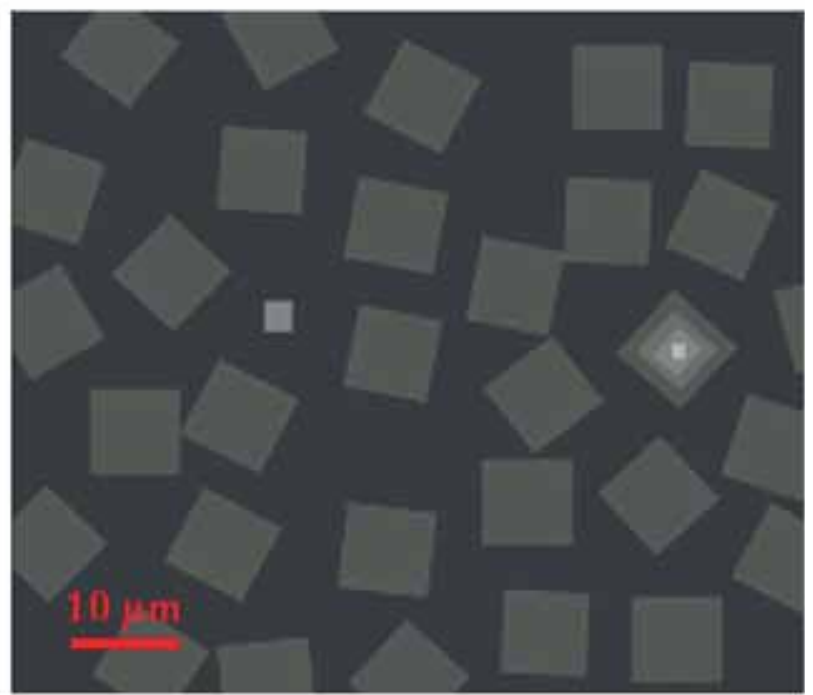

(d)

Figure 6. (a) A typical SAED pattern; (b) TEM images of APS-based $\mathrm{PEG}_{5000}-b$-PANI 7850 single crystals grown at $28^{\circ} \mathrm{C}$, bright filed (left) and dark field (right); (c) AFM height image of APS-based PANI $10050-b-\mathrm{PEG}_{35000}-b-\mathrm{PANI}_{10050}$ single crystals grown at $28^{\circ} \mathrm{C}$; and (d) STEM image of APS-based PANI $3840-b$-PEG $35000-b$-PANI 3840 single crystals grown at $28^{\circ} \mathrm{C}$.

substrate. The PANI nanofibres were excluded from this crystalline structure and created the conductive-dielectricconductive sandwiched single crystals [46]. The dominant growth fronts for these single crystals were (120) reflecting the square lateral habits. Figure $6 a$ depicts a typical SAED pattern for the sandwiched single crystals. As the crystalline substrates were composed of PEG chains, the growth environment was a dilute solution (0.009 wt\%). In addition to (120) growth planes, some others, including (040), (200), (110) and (020) were also detected. The compatibility of the growth fronts of PANI-covered, coily brush-covered [51,66,70,72], and homo-PEG [89] single crystals with each other depicted that the presence of the conductive rod PANI nanofibres did not influence the structure of single crystals and their growth planes. Totally, the grown single crystals with the PANI nano-brushes possessed the rippled edges. These non-smooth lateral habits became more remarkable by increasing the PANI blocks' molecular weight, the crystallization temperature $\left(T_{\mathrm{c}}\right)$ and also by changing the oxidant from APS to PHD. This was correlated to the more extended conformations of the PANI nano-brushes [46]. The bright and dark field TEM images of APS-based $\mathrm{PEG}_{5000}-b$-PANI 7850 single crystals grown at $28^{\circ} \mathrm{C}$, as shown in figure $6 \mathrm{~b}$, had the rippled lateral habits. Figure $6 \mathrm{c}$ illustrates the $\mathrm{PANI}_{10050}-b$ $\mathrm{PEG}_{35000}-b-\mathrm{PANI}_{10050}$ single crystals at the same $T_{\mathrm{c}}$ and based on the same oxidant with a non-smooth lateral habit. Furthermore, STEM image of the APS-based $\mathrm{PANI}_{3840}-b$ $\mathrm{PEG}_{35000}-b-\mathrm{PANI}_{3840}$ single crystals grown at $28^{\circ} \mathrm{C}$ are represented in figure $6 \mathrm{~d}$. This image reflected that the single crystals were similar from the perspective of size and lateral habit.

Here, the longer PHD-based PANI nanofibres compared to the APS-based ones were subjected to scrutiny via the growth of the respective single crystals. The APS-based 


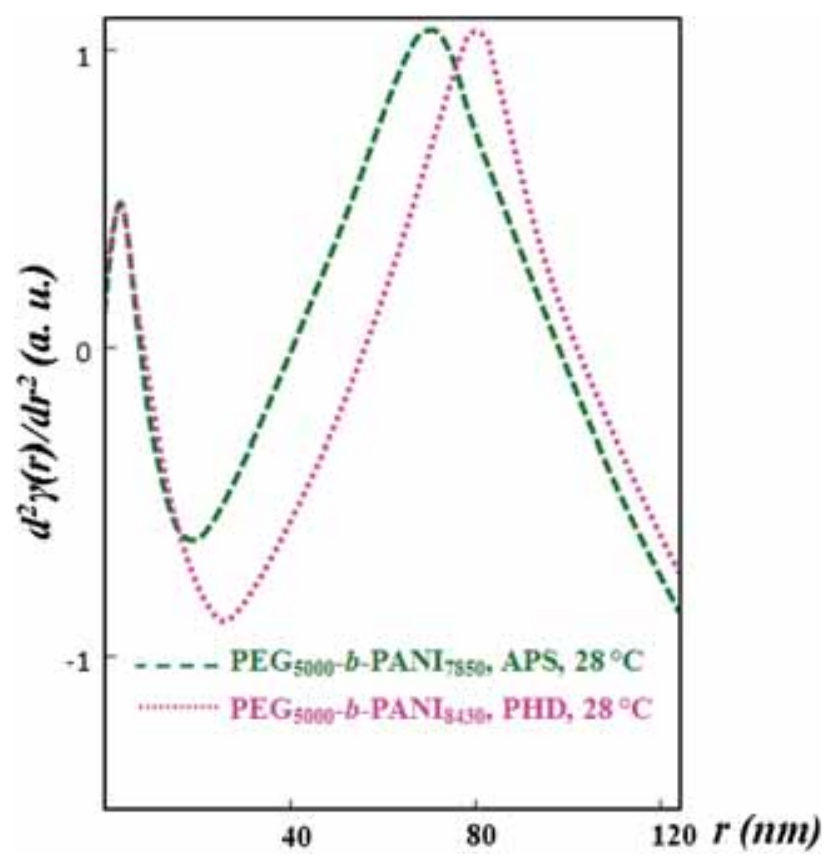

Figure 7. The IDF of SAXS for $\mathrm{PEG}_{5000}-b-\mathrm{PANI}_{7850}$ (oxidant: APS) and $\mathrm{PEG}_{5000}-b$-PANI 8430 (oxidant: PHD) single crystals grown at $T_{\mathrm{c}}=28^{\circ} \mathrm{C}$.

$\mathrm{PEG}_{5000}-b-\mathrm{PANI}_{7850}$ and PHD-based $\mathrm{PEG}_{5000}-b-\mathrm{PANI}_{8430}$ block copolymers were synthesized in a similar condition. However, the PHD oxidant led to the longer PANI nanofibres. In the IDF of SAXS analyses performed on the single crystal mats, the first peak was representative of the thickness of crystalline PEG substrate. Similarly, the second peak stood for the height of PANI nano-brushes. The IDF of SAXS for the APS-based $\mathrm{PEG}_{5000}-b-\mathrm{PANI}_{7850}$ and the PHD-based $\mathrm{PEG}_{5000}-b-\mathrm{PANI}_{8430}$ single crystals grown at $T_{\mathrm{c}}=28^{\circ} \mathrm{C}$ are reported in figure 7 to unravel the effect of two different oxidants at the same crystallization temperatures. For the mentioned single crystals, the first peaks were the same, while the second peaks were different. Therefore, by altering the oxidant type from APS to PHD, the peak of brush height shifted to the higher values. To quantitatively explain the substrate thickness of these samples was $2.80 \mathrm{~nm}$, whereas the thicknesses of the PANI brushes were 76 and $80 \mathrm{~nm}$, respectively.

For the single crystals of two other block copolymers, i.e., APS-based $\mathrm{PANI}_{3165}-b-\mathrm{PEG}_{6000}-b-\mathrm{PANI}_{3165}$ and PHDbased PANI $1_{3540}-b-\mathrm{PEG}_{6000}-b-\mathrm{PANI}_{3540}$ grown at $T_{\mathrm{c}}=28^{\circ} \mathrm{C}$, the substrate thicknesses were $3.3 \mathrm{~nm}$ and the PANI nanobrushes heights were 28 and $33 \mathrm{~nm}$, respectively. In these two single crystals, the diameters of the PANI tethered nanobrushes were 6 and $7 \mathrm{~nm}$. As another instance, for the APSbased PANI $14201-b-\mathrm{PEG}_{6000}-b-\mathrm{PANI}_{14201}$ and the PHD-based $\mathrm{PANI}_{14547}-b-\mathrm{PEG}_{6000}-b-\mathrm{PANI}_{14547}$ single crystals grown at $T_{\mathrm{c}}=28^{\circ} \mathrm{C}$, the substrate thicknesses were $3.2 \mathrm{~nm}$, while the PANI thickness were 131 and $135 \mathrm{~nm}$, respectively. Here, like the previous system, only the PANI nanofibres with 6 and $7 \mathrm{~nm}$ diameters were included in the single crystals structures.

The PANI nanofibres do not result in a real solution, instead, they form a dispersion [84]. Therefore, in the GPC analysis taken from DMF, the solubility of PANI nanofibres was not in the molecular scale. Here, the bimodal GPC traces could be related to both the length (molecule weight) and the diameter dispersity, because, the PANI nanofibres synthesized by the interfacial polymerization possessed a range of diameters.

In AFM height profiles of $\mathrm{PEG}_{5000}-b-\mathrm{PANI}_{n}$ and $\mathrm{PANI}_{n}-b$ $\mathrm{PEG}_{6000}-b-\mathrm{PANI}_{n}$ single crystals with a dispersed-dispersed surface morphology, the heights of all PANI-disperses were exactly the same. Figure $8 \mathrm{a}$ and b represents AFM height and phase images of the surface morphology related to a PHD-based $\mathrm{PANI}_{3540}-b-\mathrm{PEG}_{6000}-b-\mathrm{PANI}_{3540}$ single crystal. As illustrated in figure $8 \mathrm{c}$, AFM height profile of mentioned single crystals grown at $T_{\mathrm{c}}=28^{\circ} \mathrm{C}$ demonstrated this smoothness. The height of all PANI-disperses on the PEG substrate was $32 \mathrm{~nm}$. This smoothness satisfied the condition for all other dispersed-dispersed $\mathrm{PEG}_{5000}-b-\mathrm{PANI}_{n}$ and $\mathrm{PANI}_{n}-b-\mathrm{PEG}_{6000}-b-\mathrm{PANI}_{n}$ single crystals. For example, for $\mathrm{PEG}_{5000}-b-\mathrm{PANI}_{12850}$ single crystals synthesized by APS at $T_{\mathrm{c}}=18^{\circ} \mathrm{C}$, the thicknesses of all PANI-disperses were equal to $115 \mathrm{~nm}$. It is worth noting that in AFM height profiles, due to a conductive-dielectric-conductive sandwiched structure, the thicknesses were total. The height of the PANI nanorods was calculated through subtracting the PEG substrate thickness and, subsequently, dividing by two. The thicknesses of the crystalline substrates were directly obtained from SAXS.

In the matrix-dispersed morphologies of $\mathrm{PANI}_{n}-b$ $-\mathrm{PEG}_{35000}-b-\mathrm{PANI}_{n}$ single crystals, the PANI nano-brushes possessed a similar height in all PANI-disperses. The height variance between the matrix and disperses was not for different lengths of the PANI nanorods. Instead, this was the diameter difference of the PANI nano-brushes from which the height variance was originated. Even the minimum surface area demanded for the PANI nano-brushes with the critical diameter was not provided by the PEG lamellar substrate. Therefore, these PANIs were caused to be more extended and create the PANI-disperses. The mentioned matrix-dispersed and dispersed-dispersed morphologies were reported elsewhere with more details [46].

In $\mathrm{PEG}_{5000}-b-\mathrm{PANI}_{n}$ and $\mathrm{PANI}_{n}-b-\mathrm{PEG}_{6000}-b-\mathrm{PANI}_{n}$ single crystals, the substrate molecular weight did not affect the height of PANI-grafted nano-brushes. In these systems, only the molecular weight of PANI nanofibres (or their length) and their morphology (degree of stretching) influenced the PANI nano-brushes length. As an instance, in the dispersed-dispersed $\mathrm{PANI}_{3540}-b$ - $\mathrm{PEG}_{6000}-b-\mathrm{PANI}_{3540}$ single crystals, the thickness of PANI nano-brushes with the molecular weight of $3540 \mathrm{~g} \mathrm{~mol}^{-1}$ on the $\mathrm{PEG}_{6000}$ was $32 \mathrm{~nm}$ for all PANI-disperses. Likewise, in the disperseddispersed $\mathrm{PANI}_{4065}-b$ - $\mathrm{PEG}_{6000}-b$ - $\mathrm{PANI}_{4065}$ single crystals, 


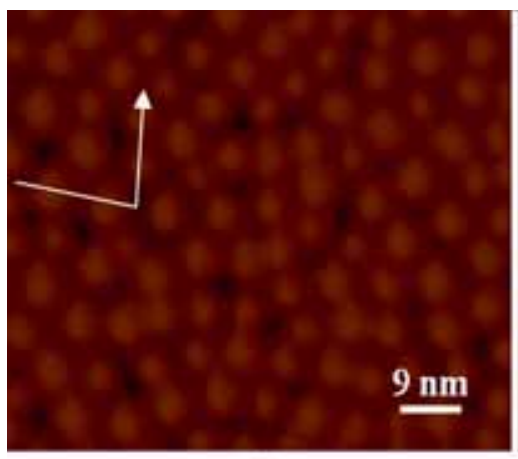

(a)

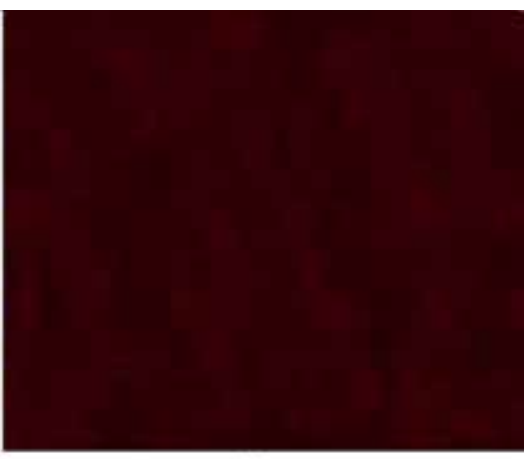

(a)

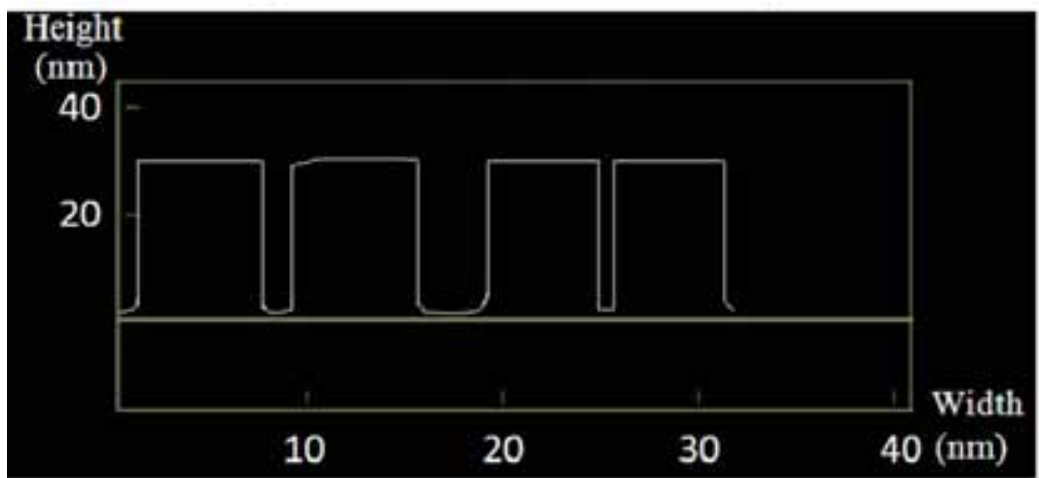

(c)

Figure 8. (a) AFM height image of $\mathrm{PANI}_{3540}-b-\mathrm{PEG}_{6000}-b$ - $\mathrm{PANI}_{3540}$ (oxidant: $\left.\mathrm{PHD}, T_{\mathrm{c}}=28^{\circ} \mathrm{C}\right)$; (b) phase image; and (c) height profile.

the PANI-disperses thickness $\left(M_{n}^{\mathrm{PANI}}=4065 \mathrm{~g} \mathrm{~mol}^{-1}\right)$ was $38 \mathrm{~nm}$. Both samples explained above were grown based on the PHD oxidant at $T_{\mathrm{c}}=23^{\circ} \mathrm{C}$. Difference between the heights of PANI disperses was obviously attributed to their various primary molecular weights (3540 vs. $\left.4065 \mathrm{~g} \mathrm{~mol}^{-1}\right)$. Furthermore, the height of matrix phase was equal to $22 \mathrm{~nm}$ in the $\mathrm{PANI}_{4065}-b-\mathrm{PEG}_{35000}-b-\mathrm{PANI}_{4065}$ single crystals. Here, as mentioned before, the matrix phase height was significantly lower than the thickness of PANI-disperses (22 vs. $38 \mathrm{~nm}$ ). In matrix phase, the PANI nanofibres diameters were lower than the critical diameter of fully extended PANIdisperses. Hence, they had more freedom on the substrate and, consequently, the lower extension. These lower extended PANI nanofibres developed a matrix phase whose thickness was considerably lower than that of fully extended PANI-disperses [46].

Here, we want to provide an estimation for the number of PANI nanofibres on the crystalline substrate of disperseddispersed single crystals. As an example, in the APS-based $\mathrm{PEG}_{5000}-b-\mathrm{PANI}_{2430}$ single crystals grown at $T_{\mathrm{c}}=28^{\circ} \mathrm{C}$ with the lateral size of $9 \mu \mathrm{m}$, the number of the grafted PANI nanofibres having the diameter of $6 \mathrm{~nm}$ was $\sim 3 \times 10^{6}$. On the other side, for the PHD-based PANI $8430-b-\mathrm{PEG}_{6000}-b$ $\mathrm{PANI}_{8430}$ single crystals grown at $T_{\mathrm{c}}=23^{\circ} \mathrm{C}$ with the same lateral size $(=9 \mu \mathrm{m})$, this number for the average diameter of $7 \mathrm{~nm}(6-8 \mathrm{~nm})$ was $\sim 2 \times 10^{6}$.
In AFM height profile of APS-based $\mathrm{PANI}_{3840}-b-\mathrm{PEG}_{35000}$ - $b$ - $\mathrm{PANI}_{3840}$ single crystals grown at $T_{\mathrm{c}}=23^{\circ} \mathrm{C}$, as illustrated in figure 9 , the height of matrix phase was $9 \mathrm{~nm}$. Meanwhile, for the PANI-disperses, the diameter and the thickness were 42 and $33 \mathrm{~nm}$, respectively. All rendered explanations demonstrated that the bimodal GPC traces of copolymers were originated from the diameter distribution of PANI nanofibres, not from the length (or molecular weight) dispersity. Furthermore, a narrower distribution of the PHD-based nanofibres compared to the APSbased ones resulted in $56-44 \%$ and $50-50 \%$ distribution for the peak areas of $\mathrm{PANI}_{16520}-b-\mathrm{PEG}_{35000}-b-\mathrm{PANI}_{16520}$ and $\mathrm{PANI}_{16100}-b-\mathrm{PEG}_{35000}-b-\mathrm{PANI}_{16100}$ copolymers, respectively (figure 5).

In $\mathrm{PEG}_{5000}-b-\mathrm{PANI}_{n}$ and $\mathrm{PANI}_{n}-b-\mathrm{PEG}_{6000}-b-\mathrm{PANI}_{n}$ single crystals, although the PHD-based PANI nanofibres had a narrower diameter distribution, both PHD- and APSbased single crystals for a given $M_{n}^{\mathrm{PEG}}$ possessed a similar dispersed-dispersed surface morphology. It was attributed to this fact that in these systems, only a limited range of diameters $(6-9 \mathrm{~nm})$ was capable of being incorporated into the single crystal structures. However, in the APS-based growth systems, due to the higher percentage of 6-9 nm PANI nanofibres (because of a wider diameter distribution of the PANI nanofibres), the single crystals were developed in a larger population. 


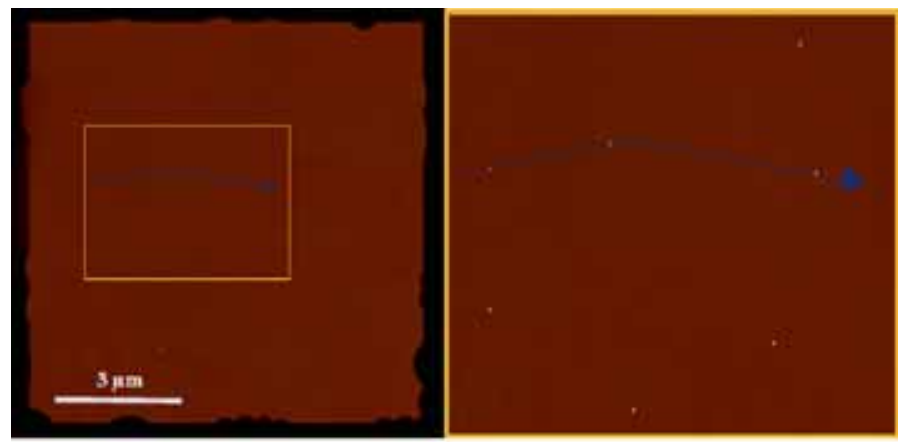

(a)

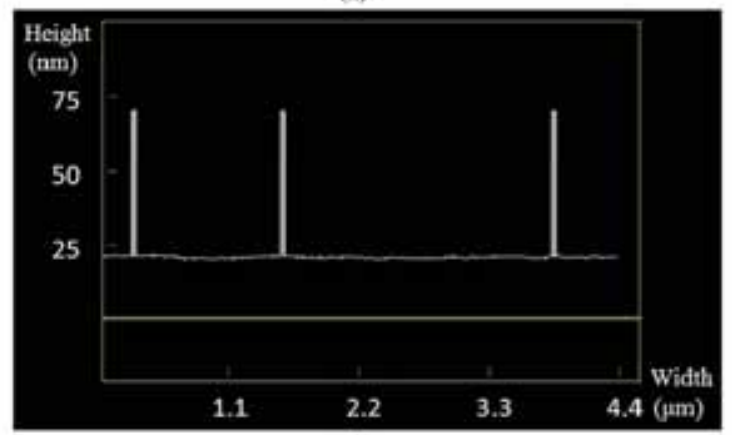

(b)

Figure 9. (a) AFM height image of $\mathrm{PANI}_{3840}-b-\mathrm{PEG}_{35000}-b$ $\mathrm{PANI}_{3840}$ (oxidant: APD, $T_{\mathrm{c}}=23^{\circ} \mathrm{C}$ ) (left) accompanied by the magnified surface morphology (right); (b) height image.

\section{Conclusions}

Copolymerization of amine-terminated PEG along with the aniline monomers carried out through interfacial polymerization using sulphuric acid as a dopant and two different kinds of oxidants, i.e., APS and PHD. The PHD-based PANI nanofibres were longer and more conductive with a narrower diameter distribution. For both APS- and PHD-based systems, the ideal diameter with the largest population was $32 \mathrm{~nm}$. Regardless of the PEG dielectric blocks presence, synthesized block copolymers were conductive; but the conductivity of the copolymers decreased as the molecular weight of the dielectric block increased. To further study these block copolymers in which the coily blocks were crystallizable, the respective single crystals were grown from the dilute solution in amyl acetate. Non-smooth rippled square single crystals were detected with the dominant (120) growth fronts. By increasing the PANI blocks molecular weight and the crystallization temperature, and also via changing the oxidant from APS to PHD, the lateral habits became more rippled. Furthermore, the bimodal GPC traces of the block copolymers were attributed to the diameter distribution of the PANI nanofibres, because all nanofibres in one block copolymer had similar lengths.

\section{References}

[1] Reneker D H and Chun I 1996 Nanotechnology 7216
[2] Dersch R, Steinhart M, Boudriot U, Greiner A and Wendorff J H 2005 Polym. Adv. Technol. 16276

[3] Ochi T 2004 Cellul. Commun. 1167

[4] Martin C R 1995 Acc. Chem. Res. 2861

[5] Sailor M J and Curtis C L 1994 Adv. Mater. 6688

[6] Wallace G G and Innis P C 2002 J. Nanosci. Nanotechnol. 2 441

[7] Huang W S, Humphrey B D and MacDiarmid A G 1986 J. Chem. Soc. Faraday Trans. 1822385

[8] MacDiarmid A G, Chiang J C, Halpern M, Huang W S, Mu S L, Somasiri N L D et al 1985 Mol. Cryst. Liq. Cryst. 121173

[9] MacDiarmid A G 1997 Synth. Met. 8427

[10] Anderson M R, Mattes B R, Reiss H and Kaner R B 1991 Science 2521412

[11] Cao Y, Smith P and Heeger A 1993 Synth. Met. 573514

[12] Chiang J C and MacDiarmid A G 1986 Synth. Met. 13193

[13] Xia Y N, Wiesinger J M, MacDiarmid A G and Epstein A 1995 J. Chem. Mater. 7443

[14] Majidi M R, KaneMaguire L A P and Wallace G G 1994 Polymer 353113

[15] Li J B, Jia Q M, Zhu J W and Zheng M S 2008 Polym. Int. 57 337

[16] Tran H D, Wang Y, D'Arcy J M and Kaner R B 2008 ACS Nano 21841

[17] Huang J X and Kaner R B 2004 J. Am. Chem. Soc. 126851

[18] Huang J X and Kaner R B 2004 Angew. Chem. Int. Ed. 435817

[19] Subramania A and Devi S L 2008 Polym. Adv. Technol. 19 725

[20] Ghenaatian H R, Mousavi M F, Kazemi S H and Shamsipur M 2009 Synth. Met. 1591717 
[21] Zhang L and Wan M 2002 Nanotechnology 13750

[22] Wei Z, Zhang Z and Wan M 2002 Langmuir 18917

[23] Li G and Zhang Z 2004 Macromulecules 372683

[24] Scherr E M, MacDiarmid A G, Manohar S K, Masters J G, Sun Y, Tang X et al 1991 Synth. Met. 41735

[25] Epstein A J and Yue J 1992 US Patent 5135696

[26] Huang J, Virji S, Weiller B H and Kaner R B 2003 J. Am. Chem. Soc. 125314

[27] Sawall D D, Villahermosa R M, Lipeles R A and Hopkins A R 2004 Chem. Mater. 161606

[28] Wu C G and Bein T 1994 Science 2641757

[29] Martin C R 1996 Chem. Mater. 81739

[30] Parthasarathy R V and Martin C R 1994 Chem. Mater. 6 1627

[31] Wang C W, Wang Z, Li M K and Li H L 2001 Chem. Phys. Lett. 341431

[32] Michaelson J C and McEvoy A 1994 J. Chem. Commun. 79

[33] Qiu H J and Wan M X 2001 J. Polym. Sci. Part A: Polym. Chem. 393485

[34] Yang Y S and Wan M X 2002 J. Mater. Chem. 12897

[35] Huang L M, Wang Z B, Wang H T, Cheng X L, Mitra A and Yan Y X 2002 J. Mater. Chem. 12388

[36] Choi S J and Park S M 2000 Adv. Mater. 121547

[37] Liu J M and Yang S C 1991 Chem. Commun. 1529

[38] MacDiarmid A G, Jones W E, Norris I D, Gao J, Johnson A T, Pinto N J et al 2001 Synth. Met. 11927

[39] He H X, Li C Z and Tao N 2001 J. Appl. Phys. Lett. 78 811

[40] Huang J, Virji S, Weiller B H and Kaner R B 2004 Chem. Eur. J. 101314

[41] Yan W, Wei Z X, Hsu C S and Wan M X 2003 Synth. Met. 136 213

[42] Marcel and Tarascon J M 2001 Solid State Ionics 14389

[43] Lu J X, Moon K S and Wong C P 2007 Polym. J. 481510

[44] Xu H, Li X and Wang G 2015 J. Power Sources 29416

[45] Zhang Q, Majumdar H S, Kaisti M, Prabhu A, Ivaska A, Österbacka R et al 2015 IEEE Trans. Electron. Devices 62 1291

[46] Nazari M, Agbolaghi S, Abbaspoor S, Gheybi H and Abbasi F 2016 Macromolecules 488947

[47] Shadi L, Karimi M, Entezami A A and Dindar Safa K 2013 Polym. Bull. 703529

[48] Gong C, Deng F, Tsui C P, Xue Z, Ye Y S, Tang C-Y et al 2014 J. Mater. Chem. A 219315

[49] Yang Z, Wu J, Yang Y, Zhou X and Xie X 2008 Chem. Eng. China 285

[50] Agbolaghi S, Nazari M, Abbaspoor S, Gheybi H and Abbasi F 2016 Polymer 92264

[51] Chen W Y, Li C Y, Zheng J X, Huang P, Zhu L, Ge Q et al 2004 Macromolecules 375292

[52] Lotz B and Kovacs A J 1966 Colloid Polym. Sci. 20997

[53] Geil P H 1973 Polymer single crystal. E Robert (ed) (Huntington, New York: Krieger Publishing Co.)

[54] Blundell D J, Keller A and Kovacs A J 1966 J. Polym. Sci. Part B: Polym. Lett. 4481

[55] Li B, Wang B B, Ferrier R C M and Li C Y 2009 Macromolecules 429394

[56] Chen W Y, Zheng J X, Cheng S Z D, Li C Y, Huang P, Zhu L et al 2004 Phys. Rev. Lett. 93028301
[57] Cai W W, Li C Y, Li L Y, Lotz B, Keating M and Marks D 2004 Adv. Mater. 16600

[58] Koutsos V, Vander Vegte E M and Hadziioannou G 1999 Macromolecules 321233

[59] Ionov L, Zdyrko B, Sidorenko A, Minko S, Klep V, Luzinov I et al 2004 Macromol. Rapid Commun. 25260

[60] Johnson P A, Gaspar M A and Levicky R 2004 J. Am. Chem. Soc. 1269910

[61] Nakashima H, Furukawa K, Ajito K, Kashimura Y and Torimitsu K 2005 Langmuir 21511

[62] Penn L S, Huang H, Sindkhedkar M D, Rankin S E, Chittenden K, Quirk R P et al 2002 Macromolecules 357054

[63] deBore B, Simon H K, Werts M P L, vander Vegte E W and Hadziioannou G 2000 Macromolecules 3349

[64] Weimer M W, Chen H, Giannelis E P and Sogah D Y $1999 \mathrm{~J}$. Am. Chem. Soc. 1211615

[65] Ejaz M, Yamamoto S, Ohno K, Tsujii Y and Fukuda T 1998 Macromolecules 315934

[66] Zheng J X, Xiong H, Chen W Y, Lee K, Horn R M V, Quirk R $\mathrm{P}$ et al 2006 Macromolecules 39641

[67] Chen Y 2005 PhD Dissertation, University of Akron

[68] Van Horn R M 2009 PhD Dissertation, University of Akron

[69] Zheng J X 2005 PhD Dissertation, University of Akron

[70] Abbaspoor S, Abbasi F and Agbolaghi S 2014 J. Polym. Res. 211

[71] Van Horn R M, Zheng J X, Sun H J, Hsiao M S, Zhang W B, Dong X H et al 2010 Macromolecules 436113

[72] Agbolaghi S, Abbasi F, Abbaspoor S and Alizadeh-Osgouei M 2015 Eur. Polym. J. 66108

[73] Abbaspoor S, Abbasi F and Agbolaghi S 2014 RSC Adv. 4 17071

[74] Agbolaghi S, Alizadeh-Osgouei M, Abbaspoor S and Abbasi F 2015 RSC Adv. 51538

[75] Rahimi K, Botiz I, Stingelin N, Kayunkid N, Sommer M, Koch F P et al 2012 Angew. Chem. Int. Ed. 5111131

[76] Wang Y, Chen J, Li S, Li L, Su Q, Wang J et al 2011 Macromolecules 441737

[77] Samanta B C, Maity T, Dalai S and Banthia A K 2008 J. Mater. Sci. Technol. 24272

[78] Gao H, Jiang T, Han B, Wang Y, Du J, Liu Z et al 2004 Polymer 453017

[79] Guan H, Fan L Z, Zhang H and Qu X 2010 Electrochim. Acta 56 964

[80] Yan L and Tao W 2007 J. Polym. Sci. Part A: Polym. Chem. 46 12

[81] Huang J and Kaner R B 2006 Chem. Commun. 367

[82] Rahy A and Yang D J 2008 Mater. Lett. 624311

[83] Zhang X, Zhu J, Haldolaarachchige N, Ryu J, Young D P, Wei S et al 2012 Polymer 532109

[84] Stejskal J and Kratochvil P 1993 Synth. Met. 61225

[85] Griesser T, Viola Radl S, Koepplmayr T, Wolfberger A, Edler M Pavitschitz A, Kratzer M et al 2012 J. Mater. Chem. 22 2922

[86] Pruneanu S 1999 J. Mater. Sci. 342733

[87] Yana J, Wei T, Fan Z, Qian W, Zhang M, Shen X et al $2010 \mathrm{~J}$. Power Sources 1953041

[88] Yoon S B, Yoon E H and Kim K B 2011 J. Power Sources 196 10791

[89] Agbolaghi S, Abbasi F and Jalili K 2014 J. Polym. Res. 211 